\title{
Onderzoek naar plastic in magen van noordse stormvogels en andere zeevogels in relatie tot het verlies van MSC-ZOE containers in begin januari 2019.
}

Auteur(s):

Jan Andries van Franeker \& Susanne Kühn

Wageningen Marine Research 
Keywords: MSC-ZOE, vogels, microplastic

Opdrachtgever: Rijkswaterstaat Noord-Nederland

Afdeling Netwerkontwikkeling en Visie

Postbus 2232

3500 GE Utrecht

Dit rapport is gratis te downloaden van https://doi.org/10.18174/531132

Wageningen Marine Research verstrekt geen gedrukte exemplaren van rapporten.

Wageningen Marine Research is ISO 9001:2015 gecertificeerd.

(C) Wageningen Marine Research

Wageningen Marine Research, instituut binnen de rechtspersoon Stichting

Wageningen Research, hierbij vertegenwoordigd door Dr. M.C.Th. Scholten, Algemeen directeur

KvK nr. 09098104,

WMR BTW nr. NL 8113.83.696.B16.

Code BIC/SWIFT address: RABONL2U

IBAN code: NL 73 RABO 0373599285
Wageningen Marine Research aanvaardt geen aansprakelijkheid voor gevolgschade, noch voor schade welke voortvloeit uit toepassingen van de resultaten van werkzaamheden of andere gegevens verkregen van Wageningen Marine Research. Opdrachtgever vrijwaart Wageningen Marine Research van aanspraken van derden in verband met deze toepassing.

Alle rechten voorbehouden. Niets uit deze uitgave mag weergegeven en/of gepubliceerd worden, gefotokopieerd of op enige andere manier gebruikt worden zonder schriftelijke toestemming van de uitgever of auteur. 


\section{Samenvatting}

Maaginhouden van in 2019 op de Waddenkust aangespoelde zeevogels zijn onderzocht op de mogelijke aanwezigheid van plastics afkomstig van het MSC ZOE container incident van 1 en 2 januari 2019. Het ging daarbij vooral om industriële polyethyleen plastic pellets en kleine polystyreen korrels. Voor de Noordse Stormvogel is goed vergelijkingsmateriaal aanwezig uit eerdere jaren.

Qua hoeveelheid plastics en de aanwezigheid van plastic pellets of polystyreen korrels werden in de stormvogelmagen en darmen geen aanwijzingen gevonden voor directe effecten van het container incident. Voor een aantal andere onderzochte soorten zeevogels is geen goed vergelijkingsmateriaal aanwezig, maar werden geen aanwijzingen gevonden voor plastics die afkomstig waren van het container incident. 


\section{Inhoud}

$\begin{array}{lr}\text { Samenvatting } & 3\end{array}$

$1 \quad$ Inleiding $\quad 5$

$2 \quad$ Materiaal en Methodes $\quad 6$

$\begin{array}{lll}3 & \text { Resultaten } & 7\end{array}$

$\begin{array}{lll}3.1 & \text { Hoeveelheid plastics in de magen } & 7\end{array}$

3.2 Details van aangetroffen pellets en microbeads $\quad 9$

4 Discussie $r$\begin{tabular}{ll}
11 \\
\hline
\end{tabular}

5 Conclusie $r \begin{array}{ll}13\end{array}$

6 Dankwoord $r$

$\begin{array}{llr}7 & \text { Kwaliteitsborging } & 15\end{array}$

$\begin{array}{lr}\text { Literatuur } & 16\end{array}$

$\begin{array}{lr}\text { Verantwoording } & 17\end{array}$

$\begin{array}{llr}\text { Bijlage } 1 \quad \text { Details stormvogels } 2019 & 18\end{array}$

$\begin{array}{llr}\text { Bijlage } 2 \quad \text { Details industriële pellets } & 19\end{array}$ 


\section{Inleiding}

Tot de mogelijke schadelijke gevolgen van het massale verlies van containers door de MSC ZOE behoort het eten van plastics door mariene organismen zoals zeevogels. Massale hoeveelheden plastic gebruiks-objecten en verpakkingsmateriaal, vooral piepschuim, vielen het meest in het oog. Ook onbekende, maar substantiële hoeveelheden industriële plastic pellets (High Density PolyEthyleen HDPE) in $25 \mathrm{~kg}$ zakken, alsmede big-bags met klein EPS granulaat (vermoedelijk rond de 11 ton) bestemd voor de productie van polystyreen piepschuim gingen verloren. De EPS bolvormige korreltjes hadden een diameter van gemiddeld $0.7 \mathrm{~mm}$ en worden hier verder aangeduid als microbeads. Verdere details over materiaal eigenschappen worden in de integrale rapportage over de ecologische consequenties van het incident met de MSC ZOE behandeld die in januari 2021 door WMR en NIOZ zal worden opgeleverd. Dit deel-rapport richt zich op plastics in de magen van dood gevonden zeevogels.
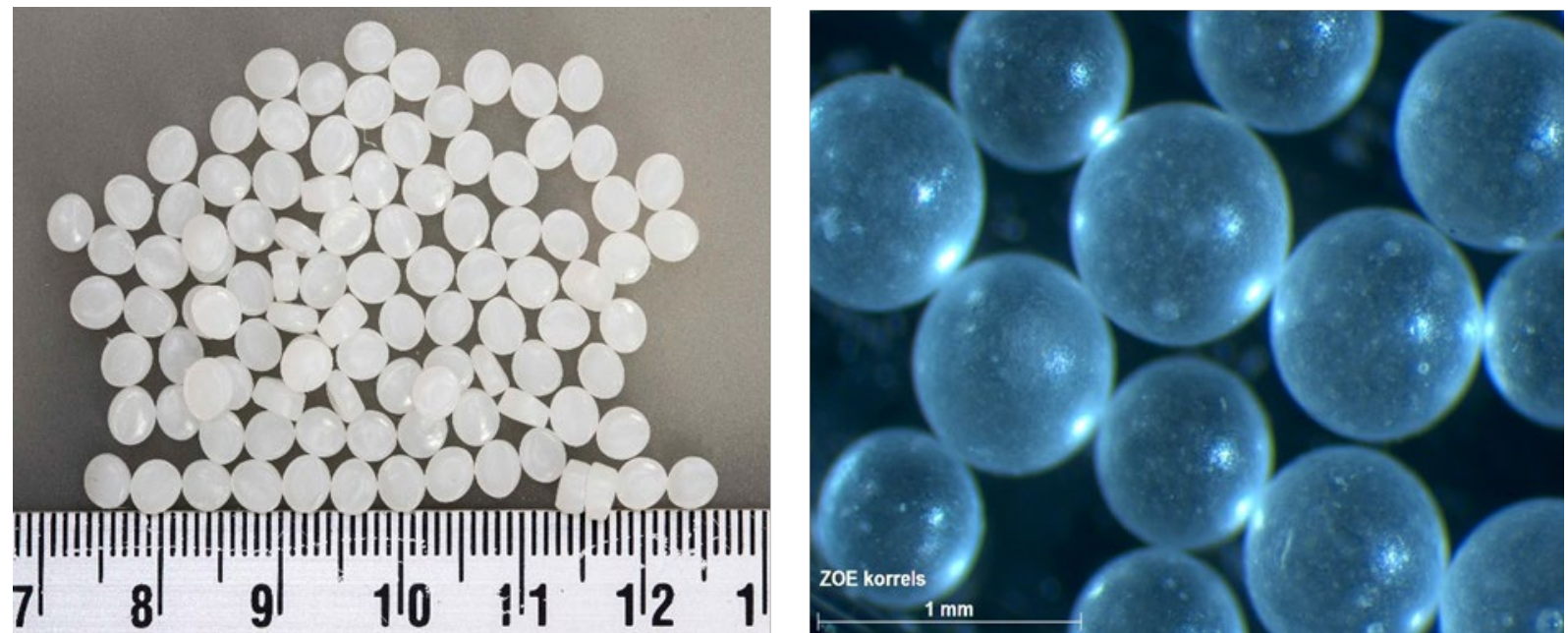

Figuur 1 ZOE lading

Een bekende zeevogelsoort die al vele jaren onderzocht wordt op het eten van plastic is de noordse stormvogel (Fulmarus glacialis; verder aangeduid als 'de stormvogel'). De hoeveelheid plastics in magen van dood aangespoelde stormvogels wordt gebruikt in de monitoring voor OSPAR (= milieuverdrag voor zeevervuiling in het noordoost Atlantisch gebied) en de Europese KRM (Kader Richtlijn Marien). Jaarlijks wordt een rapportage uitgebracht over de Nederlandse monitoring (Van Franeker en Kühn, 2020a), en meer incidenteel verschijnen rapportages over het hele Noordzeegebied (Van Franeker et.al., 2011; OSPAR, 2017, 2019). In 2019 is naar aanleiding van het verlies van de containers van MSC ZOE extra energie gestopt in de contacten met vrijwilligers of organisaties die stormvogels voor dit onderzoek verzamelen.

Deze groep is ook gevraagd om in 2019 dood aangespoelde zee-eenden (Somateria mollisima; Melanitta sp.) en drieteenmeeuwen (Rissa tridacytyla) te verzamelen. Van schelpdier etende zee-eenden en de ver op zee levende drieteenmeeuw uit de Nederlandse kustwateren bestaan incidentele publicaties over ingeslikte plastics in magen van in Nederland aangespoelde individuen (Ens et al., 2002; Van Franeker, 1983). Eerder is een omvangrijk onderzoek uitgevoerd aan de maaginhouden van zeekoeten (Uria aalge) die kort na het ZOE incident in grote aantallen dood aanspoelden (Hoofdstuk 6 in Leopold et al., 2019). In dit rapport worden daaraan de resultaten van onderzoek aan een kleiner aantal alken (Alca torda) toegevoegd.

Doel van het onderhavige rapport is om te onderzoeken of de hoeveelheden en types plastic in de magen van genoemde zeevogelsoorten afwijken van 'normaal' en of bepaalde plastics zijn toe te wijzen aan verloren lading van het ZOE container incident. Stormvogels en drieteenmeeuwen zijn daarbij voornamelijk te beschouwen als indicatoren voor plastic zwerfvuil op of nabij het wateroppervlak, terwijl schelpdier-etende zee-eenden een indicator kunnen zijn van gezonken, al dan niet door schelpdieren gegeten, materialen. Alkachtigen kunnen worden gezien als indicator voor plastics in de waterkolom, al dan niet via visprooi die mogelijk zwerfvuil had gegeten. 


\section{Materiaal en Methodes}

In totaal zijn voor dit onderzoek in de loop van 2019 verzameld: 47 stormvogels waarvan 44 met intacte magen, veertien zwarte zee-eenden ( $M$. nigra) en één grote zee-eend ( $M$. fusca), en vier intacte drieteenmeeuwen. Naar eidereenden is wel gezocht, maar er kon geen enkel intact exemplaar worden verzameld. Verreweg de meeste van de vogels werden gevonden in de Noordzee kustzone van het Waddengebied of in de Waddenzee: 38 van de stormvogels en alle zee-eenden en drieteenmeeuwen. In het genoemde onderzoek aan alkachtigen werden magen van 120 zeekoeten en twaalf alken onderzocht. Dissecties werden uitgevoerd volgens het stormvogel protocol (Van Franeker, 2004; OSPAR, 2015).

De inhoud van magen en darmen werd onderzocht op het voorkomen van vooral plastics, maar ook ander zwerfafval, inclusief industrieel getint materiaal. De magen werden opengeknipt en de inhoud zorgvuldig uitgespoeld met koud (kraan)water. In het standaardprotocol voor onderzoek bij de monitoring van plastics en ander zwerfvuil in de magen van zeevogels wordt gebruik gemaakt van een $1 \mathrm{~mm}$ zeef (van Franeker et al., 2011; OSPAR, 2015). Deze zeefmaat is voldoende om de ZOE HDPE pellets vast te houden (cylindervormig met een doorsnede van gemiddeld $4.1 \mathrm{~mm}$ (range 3.8 tot 4.4 $\mathrm{mm}$ ) en hoogte van 2.3mm; range 1.8 tot $3.0 \mathrm{~mm}$ (Kühn \& Van Franeker, 2020)). Vanwege de mogelijke aanwezigheid van klein EPS-granulaat (diameter gemiddeld $0.7 \mathrm{~mm}$; range 0.5 tot $0.9 \mathrm{~mm}$ (Kühn \& Van Franeker, 2020)) is bij het huidig onderzoek een extra zeef van $0.3 \mathrm{~mm}$ toegevoegd. De darmdelen werden enkele dagen bij kamertemperatuur geweekt in een oplossing van 5 Molair kaliumhydroxide $(\mathrm{KOH})$. Organisch materiaal zoals darmwand en aanwezig zachte prooiweefsel lost hier in op. Harde prooiresten (gehoorsteentjes van vis, kaken van inktvis, hardere resten van schaaldieren of visbotten) en harde zwerfvuil resten zoals plastics intact blijven (Kühn et al. 2017).

Alle resterende inhoud werd in petrischalen onder een binoculaire microscoop uitgezocht op de aanwezigheid van afval. Plastics en andere vormen van afval werden gesorteerd in verschillende categorieën zoals gedefinieerd door van Franeker et al. (2011). Plastics worden daarin verdeeld in de hoofdcategorieën van industriële pellets en gebruiksplastics. In dit geval is binnen de categorie 'industrieel' afzonderlijk de microbead categorie aangehouden. Binnen de gebruiksplastics wordt verder gesorteerd op subcategorieën van velvormige, draadvormige en schuimvormige plastics, hardere plastic fragmenten, en een restgroep van 'ander' plastic. De categorie 'ander zwerfvuil' bevat onder meer papier, aluminiumfolie, bewerkt hout, verfresten en keukenafval. Tot slot is een categorie 'industrieel afval' gedefinieerd waaronder bijvoorbeeld hoogovenslakken en klonten van teer of paraffine. Per (sub-)categorie werd het aantal stukjes geteld en gewogen in grammen op vier decimalen nauwkeurig. Gewichten van $0.0001 \mathrm{~g}$ en minder worden geregistreerd als $0.0001 \mathrm{~g}$. De aangetroffen industriële plastics zijn door middel van Fourier Transform Infrared Spectroscopy (FTIR) geanalyseerd op polymeer type. Voor die analyse is een Shimadzu IRSpirit gebruikt. Een laser wordt op het monster gericht en het gereflecteerd licht wordt als een spectrum weergegeven en vergeleken met een interne bibliotheek. Hiervoor worden 45 scans per meting gemaakt. Het spectrum waar de vergelijking mee wordt gemaakt, ligt tussen de 600 en de $4000 \mathrm{~nm}$.

Alle maaginhouden en darminhouden zijn dus gezeefd over zowel:

- $\quad$ een $1 \mathrm{~mm}$ zeef, d.w.z. de standaard in het OSPAR/KRM langlopend monitoring onderzoek naar de aanwezigheid van plastics in magen van Noordse Stormvogels (OSPAR 2015). Deze zeefmaat is voldoende om industriële pellets van het formaat van de uit ZOE verloren HDPE pellets of groter zwerfvuil uit te filteren.

- $\quad$ een $0.3 \mathrm{~mm}$ zeef, toegevoegd vanwege de vraag of in de maag- of darm-inhouden van onderzochte vogels klein polystyreen granulaat aanwezig is.

Per individuele vogel zijn dus in principe 4 zeefresten onderzocht (maag 1.0 en $0.3 \mathrm{~mm}$ ) en darmen ( 1.0 en $0.3 \mathrm{~mm}$ ). Het apart blijven werken met ook de $1.0 \mathrm{~mm}$ zeef was noodzakelijk in verband met het gebruik van gegevens volgens de standaard OSPAR/KRM monitoring. 


\section{Resultaten}

\subsection{Hoeveelheid plastics in de magen}

Vindgegevens van de 44 Noordse Stormvogels met bruikbare magen en de details van de plastic inhoud in magen en darmen, zijn opgenomen als Annex I bij dit rapport. De resultaten in de annex zijn die voor de optelsom samples van maag en darm, zowel van de $1 \mathrm{~mm}$ als de $0.3 \mathrm{~mm}$ zeefmaten. Industriële pellets werden in 20 van de 44 stormvogels gevonden, bijna altijd in de maag, maar in twee vogels ook in de darm. Twee microbeads werden gevonden in de darm van één stormvogel. Zoals gebruikelijk werd de totale hoeveelheid plastic in deze dieren vooral bepaald door de gebruiksplastics (verder uitgewerkt in Tabel 2).

Tabel 1 Details voor gevonden plastic in het maagdarm-systeem van verschillende zeevogelsoorten in 2019. Voor de stormvogel zijn referentie waardes voor plastics > $1 \mathrm{~mm}$ in magen beschikbaar uit de periode 2014-2018. Het onderzoek in 2019 betrof de volledige inhoud van maag plus darmen op plastic partikels $>0.3 \mathrm{~mm}$. Voor een correcte vergelijking met de 2014-2018 periode zijn de 2019 gegevens van de stormvogel ook gegeven voor de analyse van alleen de maaginhoud op partikelgrootte $>1 \mathrm{~mm}$. Aangegeven zijn het aantal onderzochte vogels, het percentage van vogels waarin de plastic categorie voorkomt (\%FO) en gemiddeld aantal (avg n) voor afzonderlijk pellets, microbeads, en alle plastics gecombineerd (=inclusief gebruiksplastics). Aan de laatste categorie is ook het gemiddeld plastic totaalgewicht in de maag (avg g; in gram) toegevoegd.

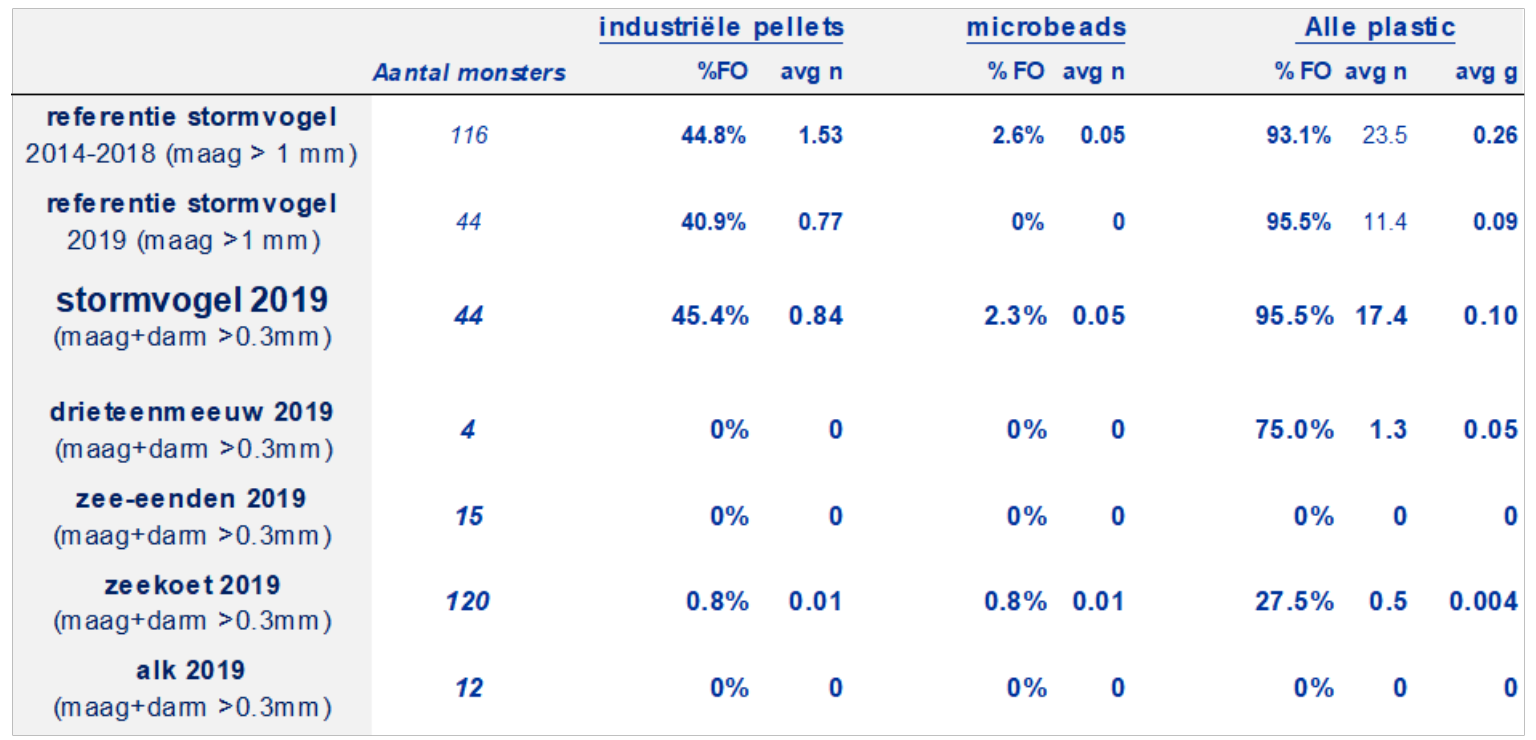

Een directe vergelijking naar eerdere jaren, als standaard in de stormvogelmonitoring het gemiddelde over een periode van vijf jaar, wordt bemoeilijkt omdat de standaardmonitoring alleen de over een $1 \mathrm{~mm}$ zeef uitgespoelde maaginhoud betreft. Daarom zijn in tabel 1 niet alleen de monitoring gegevens uit de voorgaande 2014-2018 periode gegeven, maar ook de direct vergelijkbare waardes voor plastics in de magen in 2019. Te zien is dat toevoegen van de darmplastics en kleine plastics gevonden op $0.3 \mathrm{~mm}$ zeefmaten weliswaar in totaal aantal stukjes van vooral gebruiksplastics een verhoging oplevert, maar niet substantieel voor pellets of microbeads. Het totaal gewicht aan plastic van maag plastic plus darm samples, 1.0 en $0.3 \mathrm{~mm}$ tezamen, was ongeveer $10 \%$ hoger dan wanneer alleen zoals in de standaard monitoring, naar de maag en partikels groter dan $1 \mathrm{~mm}$ was gekeken. Tabel 2 geeft meer details over de verschillende categorieën plastic in magen van stormvogels. De vergelijking betreft de 5-jaarsperiode 2014-2018 en het jaar 2019, voor plastics gevonden in de magen op zeefgrootte $1.0 \mathrm{~mm}$. 
Tabel 1

Detailvergelijking van nader gecategoriseerde hoeveelheden plastic in stormvogelmagen voorafgaand en na het ZOE incident (5-jaars periode 2014-2018 vergeleken met 2019). Kolomnamen zijn omschreven in het bijschrift bij Tabel 1.

\begin{tabular}{|c|c|c|c|c|c|c|}
\hline & \multicolumn{3}{|c|}{ 2014-2018 $(n=116)$} & \multicolumn{3}{|c|}{$2019(n=44)$} \\
\hline & $\% \mathrm{FO}$ & $\operatorname{avg} n$ & avg $g$ & $\% \mathrm{FO}$ & $\operatorname{avg} n$ & $\operatorname{avg~} \mathrm{g}$ \\
\hline industriële pellets & $44.8 \%$ & 1.5 & 0.032 & $40.9 \%$ & 0.8 & 0.018 \\
\hline microbeads & $2.6 \%$ & 0.1 & 0.000 & $0.0 \%$ & 0.0 & 0.000 \\
\hline vellen & $48.3 \%$ & 3.6 & 0.030 & $52.3 \%$ & 1.2 & 0.005 \\
\hline draden & $31.9 \%$ & 1.1 & 0.007 & $45.5 \%$ & 1.8 & 0.006 \\
\hline schuimvormig & $43.1 \%$ & 2.6 & 0.019 & $27.3 \%$ & 1.7 & 0.007 \\
\hline fragmenten & $86.2 \%$ & 14.5 & 0.111 & $81.8 \%$ & 5.5 & 0.044 \\
\hline anders & $11.2 \%$ & 0.3 & 0.058 & $22.7 \%$ & 0.5 & 0.013 \\
\hline ALLE PLASTICS & $93.1 \%$ & 23.5 & 0.257 & $95.5 \%$ & 11.4 & 0.093 \\
\hline
\end{tabular}

In de magen van drie van de vier drieteenmeeuwen werden in totaal 6 stukjes gebruiksplastic gevonden, allen op de $1 \mathrm{~mm}$ zeef. Geen pellets of microbeads werden gevonden.

In de magen of darmen van de vijftien zee-eenden (veertien zwarte en één grote) werd in het geheel geen plastic zwerfvuil aangetroffen.

In 33 van 120 zeekoeten (27.5\%) werd plastics aangetroffen. In verreweg de meeste gevallen waren dit draadvormige stukjes, maar ook één pellet, en één microbead werden aangetroffen.

In de magen en darmen van 12 Alken uit begin 2019 werden géén plastics aangetroffen. 


\subsection{Details van aangetroffen pellets en microbeads}

Details van alle industriële pellets (36) die in magen (34) of darmen (2) van stormvogels werden aangetroffen zijn opgenomen in annex II. Volgens de FTIR polymeer analyse betroffen het veelal pellets van PolyEthyleen (PE). In veel gevallen waren deze pellets uit de vogels op basis van FTIR analyses niet te onderscheiden van pellets die uit $25 \mathrm{~kg}$ zakken van de ZOE waren verzameld. Als een 'gemiddeld ZOE spectrogram' aan de standaard vergelijkingsbibliotheek werd toegevoegd, bleken 17 van de $36(47 \%)$ pellets uit stormvogelmagen daarvan niet te onderscheiden (gemerkt * in Annex II). Maar ter vergelijking, in een eerder sample van 30 pellets uit de maag en darm van een stormvogel uit het jaar 2010 bleken maar liefst 24 stuks (80\%) niet te onderscheiden van het spectogram van de latere ZOE pellets. Op basis van het uiterlijk, d.w.z. de combinatie van vorm en kleur, leek geen enkele van de stormvogel pellets uit 2019 goed vergelijkbaar met de ZOE HDPE pellets, maar dat is een subjectief oordeel. Een voorbeeld van het uiterlijk van pellets is te zien op Foto 2. Zie voor vergelijkbare foto's van plastics uit magen van alle individuele stormvogels de illustraties in Van Franeker \& Kühn, 2020b. Aanvullende fysische of chemische bepalingen om de pellets uit de magen van stormvogels te vergelijken met die uit de ZOE containers, waren in dit onderzoek niet mogelijk.

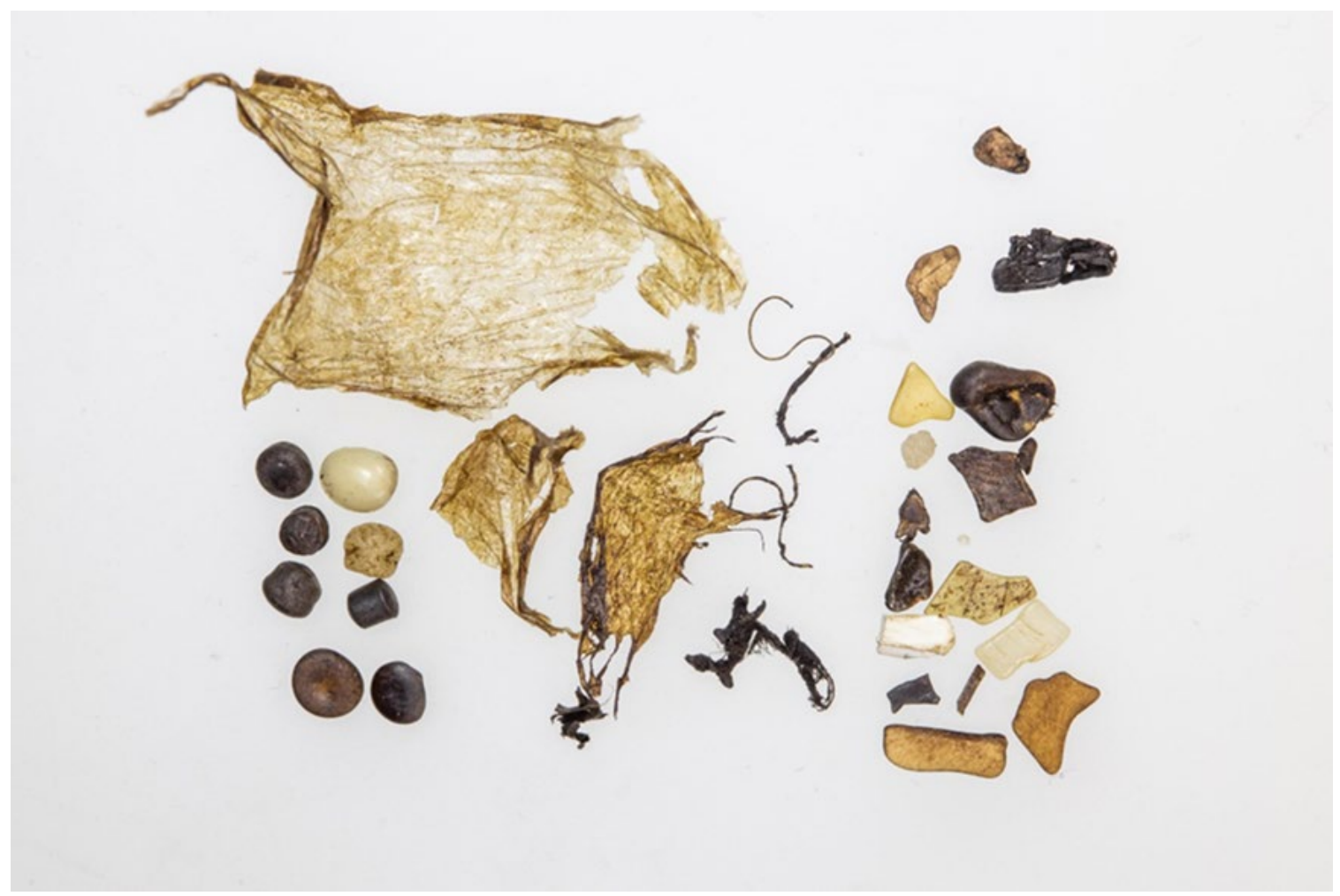

Foto 2 Plastics uit stormvogel NET-2019-047 (maaginhoud $>1 \mathrm{~mm}$ ) Naast een voor dit jaar ongebruikelijk hoog aantal industriële pellets zijn diverse plastic vellen, draden en hardere fragmenten zichtbaar. Geen enkele van deze pellets lijken qua vorm- en kleur-combinatie afkomstig te zijn van de ZOE containers. Zie ook Annex II en Van Franeker \& Kühn 2020 b.

De enige microbeads die werden aangetroffen zaten in de darminhoud van stormvogel NET2019-032 (Foto 3). Deze objecten waren te klein en te bros om veilig aan de voor FTIR analyse benodigde druk te onderwerpen, maar kleur uiterlijk en kristallijne structuur van deze microbeads lijken geenszins op het door ZOE verloren EPS granulaat. 


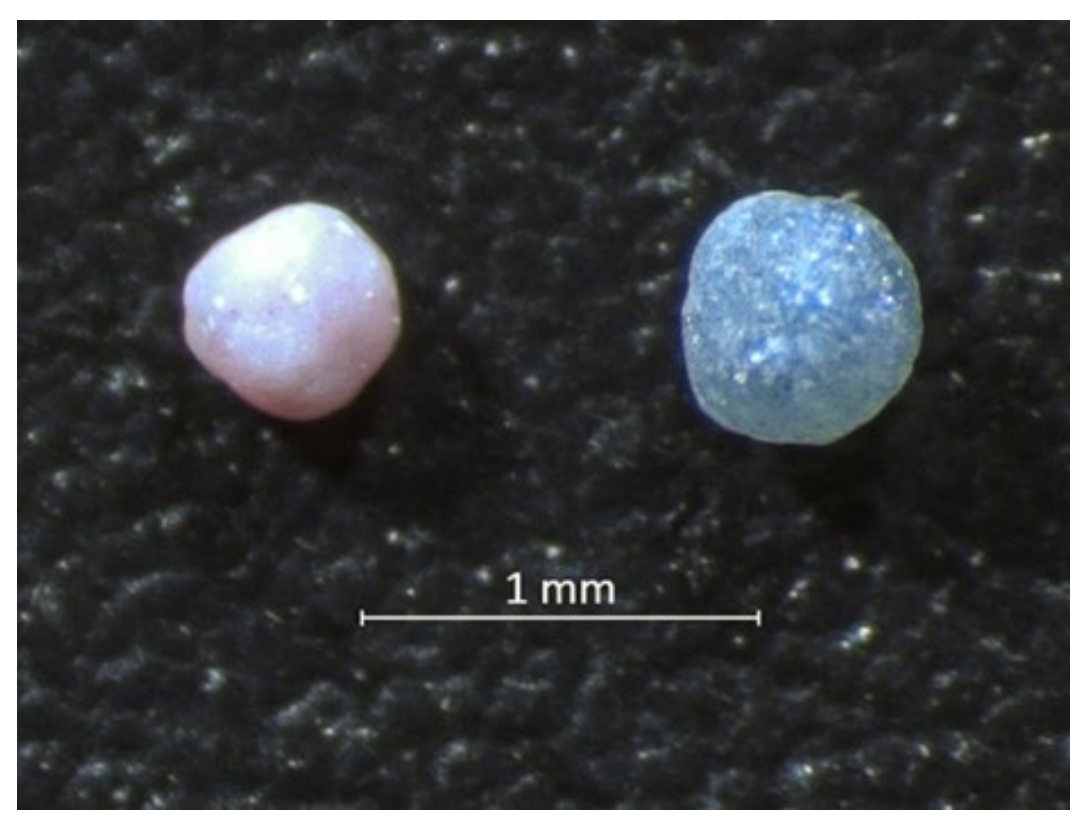

Foto 2 De enige twee microbeads die in de onderzochte stormvogels uit 2019 zijn aangetroffen (uit darminhoud van stormvogel NET-2019-032 op 0.3 mm zeef; zie ook Van Franeker \& Kühn 2020b).

In de 120 onderzochte zeekoeten (Leopold et al. 2019) was één vogel met een pellet, en één vogel met een enkele microbead. De pellet was bruinzwart van kleur en bestond uit polypropyleen (PP). De enige microbead was wit, had een diameter van ongeveer $5 \mathrm{~mm}$ en betrof geen polystyreen, maar bestond voornamelijk uit Carboxylmethyl cellulose.

In magen of darmen van drieteenmeeuwen, zee-eenden en werden géén pellets en géén microbeads aangetroffen. 


\section{Discussie}

Voor een referentie naar de 'normale' hoeveelheid plastics in magen van stormvogels, kan het best gekeken worden naar de in die monitoring gebruikelijke 5-jaars periodes. Getallen voor individuele jaren kunnen door afwijkende omstandigheden of beperkte monstergrootte fluctueren. De dataset voor het ZOE jaar 2019, met het aantal van 44 onderzochte maaginhouden kan worden beschouwd als betrouwbaar. Dit volgt uit de pilotstudy voor de stormvogelmonitoring (Van Franeker \& Meijboom, 2002) waarin uit eerdere jaarreeksen bleek dat een aantal van rond de 40 vogels in principe een betrouwbare schatting oplevert voor de hoeveelheid plastics in stormvogelmagen in het onderzochte gebied en periode.

$\mathrm{Bij}$ de beschouwing van de data moet wel rekening worden gehouden met het feit dat in 2019 vanwege de kleine 'ZOE-microbeads' zowel maag en darmen zijn uitgespoeld over zowel een $1 \mathrm{~mm}$ als een $0.3 \mathrm{~mm}$ zeef, terwijl de standaard stormvogel-monitoring (OSPAR 2015) zich beperkt tot de maaginhoud gezeefd over een $1 \mathrm{~mm}$ maaswijdte. Daarom geeft Tabel 1 de gegevens uit 2019 volgens zowel het speciale ZOE protocol als volgens het standaard OSPAR protocol. Qua plastic gewicht levert het toevoegen van de darm en kleine plastics een verhoging van ongeveer $10 \%$.

Maar de methodologische details lijken van weinig belang, want beide waardes (ZOE of OSPAR protocol) voor 2019 liggen beduidend onder de hoeveelheid plastics die gemiddeld over de 116 magen van stormvogels in de voorgaande 2014-2018 periode werden gevonden (Tabel 1). Dit geldt voor alle categorieën plastic (Tabel 2), inclusief subcategorieën als velvormig en piepschuim materiaal die massaal vrijkwamen uit de verloren containers. Afnemende hoeveelheden plastic in magen van in Nederland gevonden stormvogels zijn een uit de jaarlijkse monitoring bekende trend (Van Franeker \& Kühn 2019, 2020a). Het ZOE incident heeft hierop geen merkbare invloed gehad.

Tabel 2 Jaarlijks voorkomen van plastics in magen van in Nederland gevonden stormvogels. Ter aanvulling op tabellen 1 en 2 die zich richten op gemiddelde waardes uit de 2014-2018 periode. Losse jaargemiddeldes zijn soms niet betrouwbaar vanwege een beperkte monstergrootte of exceptionele gebeurtenissen. Het is zonder meer duidelijk dat in het jaar 2019 het ZOE incident geen merkbare invloed heeft gehad op de hoeveelheden gegeten plastic door stormvogels in ons kustgebied.

\begin{tabular}{|c|c|c|c|c|}
\hline \multicolumn{2}{|c|}{ Netherlands } & \multicolumn{3}{|c|}{ Total plastics } \\
\hline YEAR & $\begin{array}{c}\text { sample } \\
n\end{array}$ & $\%$ FO & $\begin{array}{c}\text { average number } \\
n \pm \mathbf{s e}\end{array}$ & $\begin{array}{c}\text { average mass } \\
\mathrm{g} \pm \mathrm{se}\end{array}$ \\
\hline 2014 & 12 & $100 \%$ & $21.4 \pm 3.9$ & $0.36 \pm 0.14$ \\
\hline 2015 & 23 & $96 \%$ & $12.1 \pm 3.2$ & $0.26 \pm 0.15$ \\
\hline 2016 & 31 & $87 \%$ & $31.7 \pm 12.9$ & $0.29 \pm 0.10$ \\
\hline 2017 & 38 & $92 \%$ & $26.8 \pm 14.1$ & $0.24 \pm 0.07$ \\
\hline 2018 & 12 & $100 \%$ & $15.8 \pm 7.8$ & $0.12 \pm 0.06$ \\
\hline 2019 & 44 & $95 \%$ & $11.1 \pm 2.2$ & $0.09 \pm 0.01$ \\
\hline
\end{tabular}


Hoewel zekerheid bij een deel van de industriële pellets niet kan worden geboden, lijken de door stormvogels gegeten pellets overwegend of geheel niet gerelateerd aan de melkwitte HDPE pellets uit de containers. De weinige gevonden microbeads zijn niet in verband te brengen met het ZOE ongeluk.

Voor de andere onderzochte soorten zijn geen echt goede referenties te vinden voor de 'normale' hoeveelheden ingeslikte plastics. Beschikbare referenties zijn veelal afkomstig uit totaal andere gebieden of tijdsperiodes. Kühn en Van Franeker (2020) melden in hun overzicht dat voor Drieteenmeeuwen de samengevoegde gegevens uit 9 publicaties erop neerkomen dat onder 574 onderzochte vogels 46 dieren plastic in de maag hadden (8\%). Een oude studie van de Nederlandse kust (Van Franeker, 1983) vond onder 32 drieteenmeeuwen 37.5\% met plastic in de maag. Het sample van vier drieteenmeeuwen uit 2019 is veel te klein voor een vergelijking: de gevonden stukjes plastic zijn niet toe te wijzen aan ZOE materiaal.

De afwezigheid van plastics in de magen van zwarte en grote zee-eenden lijkt te worden bevestigd in de literatuur: Kühn en Van Franeker (2020) vonden 5 studies waarbij bij in totaal 58 onderzochte eenden van het genus Melanitta geen plastics werd gevonden. Ongepubliceerde gegevens van Mardik Leopold over dieetonderzoek tussen 1993-2018, melden maaganalyses van 111 zwarte zee-eenden uit het Nederlands Waddengebied en 32 uit het Duitse Waddengebied zonder enig plastic in de maag. In veertien Zwarte Zee-eenden van elders langs de Hollandse kust had één vogel een stukje 'touw' (materiaal onbekend) in de maag. Een enkele grote zee-eend uit het Waddengebied uit 2009 had geen plastic in de maag.

Voor de zeekoet melden Leopold et al. (2019) dat vergelijking met zeekoetgegevens uit de literatuur moeilijk is, onder meer door gebruik van verschillende onderzoeksmethodes. Kühn en Van Franeker (2020) vonden in totaal 9 studies, waarin plastics werden gevonden in 45 individuen onder 814 onderzochte exemplaren (6\%). Oud Nederlands onderzoek meldde onder 210 zeekoeten $2.9 \%$ plastic in de maag (Van Franeker, 1983). Met plastics in 27.5\% van de in 2019 kort na het ZOE incident aangespoelde zeekoeten, is de situatie nu dus duidelijk anders. Echter het aangetroffen materiaal betrof in de meeste gevallen oude fragmenten van netten of touwen, en geen aan de ZOE te relateren plastics.

Voor wat betreft alken vermelden Kühn \& Van Franeker (2020) vier literatuurbronnen die gezamenlijk in 108 onderzochte magen één keer plastic vonden (1\%). Voor wat betreft Nederland in begin jaren tachtig vond Van Franeker (1983) in 82 alken twee gevallen van plastic in de maag (2.4\%). 


\section{Conclusie}

De conclusie uit dit deelonderzoek is dat het ongeval met MSC ZOE bij de onderzochte soorten zeevogels uit het Nederlands waddengebied in 2019 niet tot waarneembaar verhoogde hoeveelheden of types opgegeten plastics heeft geleid. Een relevante factor is uiteraard dat er permanent aanzienlijke plastic vervuiling op zee aanwezig is die wel in de loop van de tijd aan het afnemen is. Het jaar 2019 past in de afnemende trend. Mogelijk speelt het een rol dat met aanhoudende sterke noordenwind na het incident veel plastic, vooral piepschuim en ander verpakkingsmateriaal maar ook zwaardere stukken snel naar de kust is gewaaid, een lot dat ook het kleiner materiaal zoals de HDPE pellets trof (Van der Heide 2019). Materiaal dat niet aldus verdwenen is, is ten dele naar de bodem gezakt of met de reststroom richting Duitse bocht of naar verder noordelijke gebieden gestroomd. De conclusie dat bij in Nederland aangespoelde zeevogels geen toename van de hoeveelheid ingeslikt plastic of ander effect is waargenomen, vormt geen bewijs dat er niet elders wel gevolgen zijn opgetreden. Of op grotere afstand van de ramplocatie wel merkbare effecten onder zeevogels zijn opgetreden is op dit moment niet bekend. 


\section{Dankwoord}

De personen of instanties die de voor deze rapportage gebruikte vogels hebben aangeleverd staan vermeld in Annex I. We zijn hen dankbaar voor hun behulpzaamheid. Maar naast deze personen zijn er véél meer personen en organisaties die in 2019, maar ook in de voorgaande vergelijkingsjaren hulp hebben geboden in het steeds maar weer afzoeken van de kust. Ook wanneer dat geen resultaat opleverde is zulke inzet essentieel, en daarvoor zijn we zeer dankbaar. Mardik Leopold was de belangrijke trekker voor het zeekoet en alk-onderzoek in 2019, we zijn hem en alle in het zeekoet rapport genoemde personen zeer dankbaar. 


\section{Kwaliteitsborging}

Wageningen Marine Research beschikt over een ISO 9001:2015 gecertificeerd kwaliteitsmanagementsysteem. Dit certificaat is geldig tot 15 december 2021. De organisatie is gecertificeerd sinds 27 februari 2001. De certificering is uitgevoerd door DNV GL. 


\section{Literatuur}

Ens, B.J., Borgsteede, F.H.M., Camphuysen, C.J., Dorrestein, G.M., Kats, R.K.H., \& Leopold, M.F., 2002. Eidereendensterfte in de winter 2001-2002. Alterra-rapport 521. Alterra, Wageningen, $113 p p$.

Kühn, S., Van Werven, B., Van Oyen, A., Meijboom, A., Bravo Rebolledo, E.L. \& Van Franeker, J.A., 2017. The use of potassium hydroxide $(\mathrm{KOH})$ solution as a suitable approach to isolate plastics ingested by marine organisms. Marine Pollution Bulletin 115: 86-90. http://dx.doi.org/10.1016/j.marpolbul.2016.11.034

Kühn, S. \& Van Franeker, J.A., 2020. Tussenrapport Factsheet plastics verloren door de MSC Zoe.. Wageningen Marine Research Internal Report, April 2020, 6pp.

Leopold, M.F., Kik, M., Van Tulden, P., Van Franeker, J.A., Kühn, S., \& Rijks, J., 2019. De Zoe en de zeekoet - Een onderzoek naar de doodsoorzaak en de herkomst van de zeekoeten die massaal strandden op de Nederlandse kust in januari en februari 2019.. Wageningen Marine Research Rapport C26-19. Den Helder. 59pp. https://doi.org/10.18174/472854

OSPAR, 2015. Guidelines for Monitoring of plastic particles in stomachs of fulmars in the North Sea area.. OSPAR Commission Agreement 2015-03 (Source: EIHA 15/5/12 Add.1). 26pp. http://www.ospar.org/convention/agreements?q=fulmar\&t=32281\&a=\&s=

OSPAR, 2017. OSPAR Intermediate Assessment 2017. Plastic Particles in Fulmar Stomachs in the North Sea. OSPAR Assessment Portal OAP online document: https://oap.ospar.org/en/osparassessments/intermediate-assessment-2017/pressures-human-activities/marine-litter/plasticparticles-fulmar-stomachs-north-sea/

OSPAR, 2019. OSPAR Committee Assessment: Plastic particles in fulmar stomachs in the North Sea. OSPAR Assessment Portal (OAP) Online Document. https://oap.ospar.org/en/osparassessments/committee-assessments/eiha-thematic-assessments/marine-litter/plastic-particlesin-fulmar-stomachs-north-sea/.

Van der Heide, T., 2019. Position paper ecologie voor ronde tafel gesprek afhandeling containerramp MSC Zoe.. Brief aan de vaste commissie voor Infrastructuur en Waterstaat van de Tweede Kamer der Staten-Generaal, 30 maart 2019, NIOZ \& RUG.

https://www.tweedekamer.nl/debat en vergadering/commissievergaderingen/details?id=2019A00 $\underline{440}$

Van Franeker, J.A., 1983. Inwendig onderzoek aan zeevogels. (Dissection of seabirds). Nieuwsbrief NSO 4(4/5): 144-167. http://natuurtijdschriften.nl/download?type=document\&docid $=551849$

Van Franeker, J.A. \& Meijboom, A., 2002. Litter NSV - Marine litter monitoring by Northern Fulmars: a pilot study. ALTERRA-Rapport 401. (Alterra, Wageningen, 72pp). http://edepot.wur.nl/45695

Van Franeker, J.A., 2004. Save the North Sea - Fulmar Study Manual 1: Collection and dissection procedures. Alterra Rapport 672. Alterra, Wageningen. 38pp . http://edepot.wur.nl/40451

Van Franeker, J.A., Blaize, C., Danielsen, J., Fairclough, K., Gollan, J., Guse, N., Hansen, P.L., Heubeck, M., Jensen, J.-K., Le Guillou, G., Olsen, B., Olsen, K.O., Pedersen, J., Stienen, E.W.M. \& Turner, D.M., 2011. Monitoring plastic ingestion by the northern fulmar Fulmarus glacialis in the North Sea. Environmental Pollution 159: 2609-2615. http://dx.doi.org/10.1016/j.envpol.2011.06.008

Van Franeker, J.A. \& Kühn, S., 2019. Fulmar Litter EcoQO monitoring in the Netherlands - Update 2018. Wageningen Marine Research Report C077/19 \& RWS Centrale Informatievoorziening BM 19.16. Den Helder, 60pp. https://doi.org/10.18174/486799.

Van Franeker, J.A. \& Kühn, S., 2020a. Fulmar Litter EcoQO monitoring in the Netherlands - Update 2019. Wageningen Marine Research Report C074/20 \& RWS Centrale Informatievoorziening BM 20.16. Den Helder, 62pp https://doi.org/10.18174/529399.

Van Franeker, J.A. \& Kühn, S., 2020b. Finders Information Netherlands (2019). SNS Fulmar Study Report - Findersinformation_NL_6thBatch2019, Wageningen Marine Research, Den Helder, 63pp. https://doi.org/10.18174/530532 


\section{Verantwoording}

Rapport C078/20

Projectnummer: 4315100134-5

Dit rapport is met grote zorgvuldigheid tot stand gekomen. De wetenschappelijke kwaliteit is intern getoetst door een collega-onderzoeker en het verantwoordelijk lid van het managementteam van Wageningen Marine Research

Akkoord:

Edwin Foekema

Onderzoeker

Handtekening:

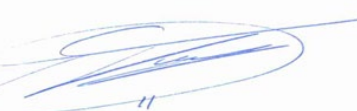

Datum:

30 september 2020

Akkoord:

Dr. J. Asjes

Manager Integration

Handtekening:

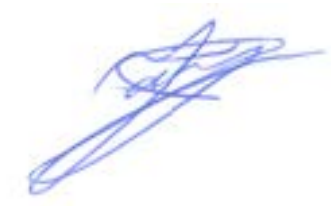

Datum:

30 september 2020 


\section{Bijlage 1 Details stormvogels 2019}

Details van in 2019 in Nederland gevonden stormvogels en de plastics in de maag-darm inhoud (gezeefd over 1.0 en $0.3 \mathrm{~mm}$ ) zeven. De hier gegeven resultaten verschillen dus iets van de monitoring gegevens in Van Franeker \& Kühn (2020), die zijn gebaseerd op maaginhoud gezeefd op $1.0 \mathrm{~mm}$. Toevoegen van darminhoud en $0.3 \mathrm{~mm}$ zeefmaat voegt $\pm 10 \%$ toe aan het plastic gewicht.

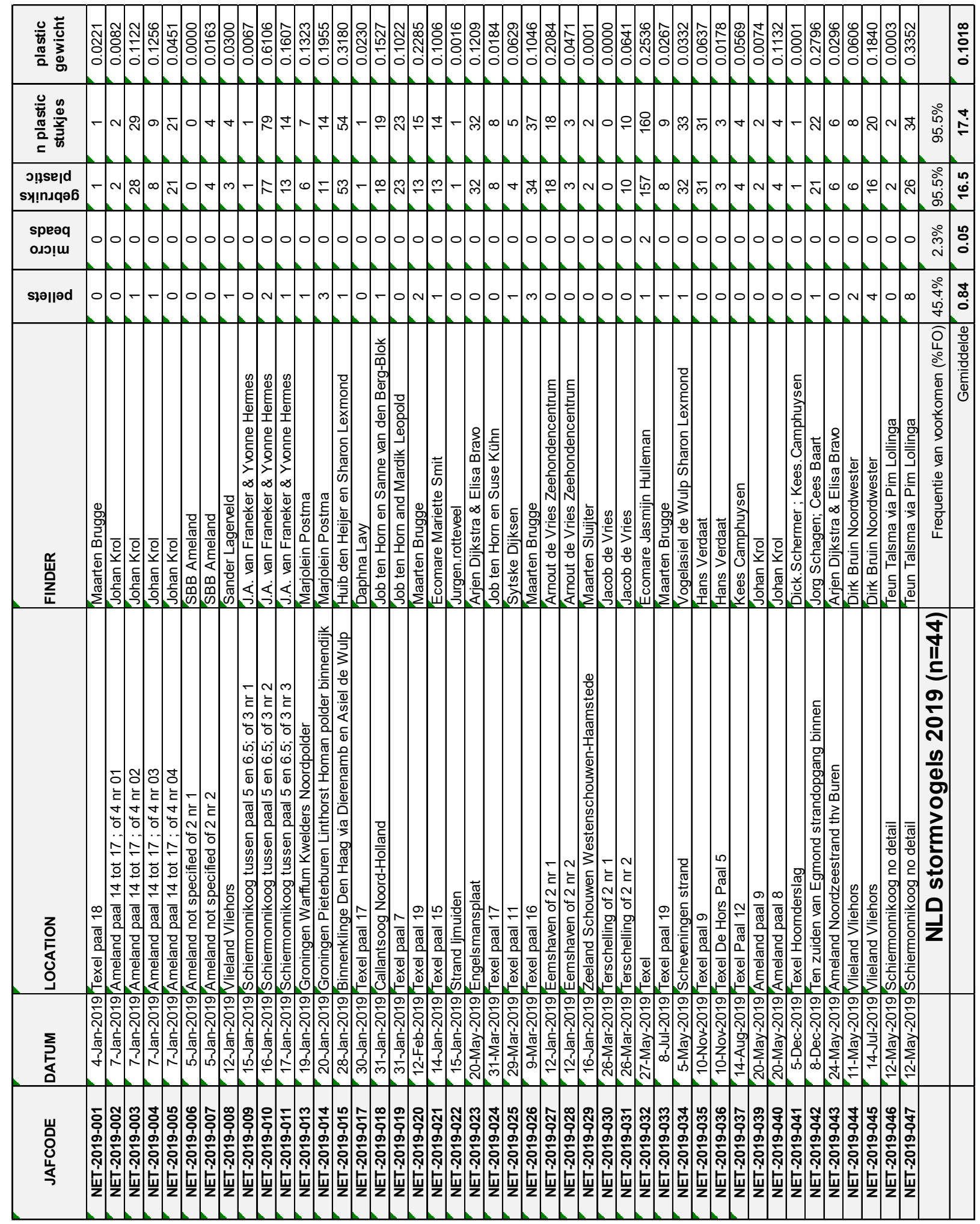




\section{Bijlage 2 Details industriële pellets}

Details van in 2019 in stormvogelmagen/darmen aangetroffen industriële pellets

\begin{tabular}{|c|c|c|c|c|c|c|c|}
\hline pellet identifier & $\begin{array}{l}\text { length } \\
(\mathrm{mm})\end{array}$ & $\begin{array}{l}\text { width } \\
(\mathrm{mm})\end{array}$ & $\begin{array}{l}\text { height } \\
(\mathrm{mm})\end{array}$ & mass $(\mathrm{g})$ & Polymer by FTIR & $\begin{array}{l}\text { Match } \\
\text { score }\end{array}$ & \\
\hline NET-2019-003_I_IND-001 & 4.2 & 4 & 2.1 & 0.0214 & HDPE & $95 \%$ & * \\
\hline NET-2019-004_M_IND-001 & 3.4 & 3.1 & 4.5 & 0.0301 & PE & $96 \%$ & * \\
\hline NET-2019-008_M_IND-001 & 2.8 & 2.4 & 2.5 & 0.0164 & Paraffin & $83 \%$ & \\
\hline NET-2019-010_M_IND-001 & 4.2 & 4 & 2 & 0.0188 & PE & $92 \%$ & \\
\hline NET-2019-010_I_IND-001 & 3 & 2.9 & 0.7 & 0.0012 & Styrene & $88 \%$ & \\
\hline NET-2019-011_M_IND-001 & 4.8 & 4.5 & 2.4 & 0.0257 & $\mathrm{PE}$ & $93 \%$ & * \\
\hline NET-2019-013_M_IND-001 & 3.4 & 3.3 & 4.9 & 0.0327 & PE & $94 \%$ & * \\
\hline NET-2019-014_M_IND-001 & 3.6 & 3.3 & 3.7 & 0.0209 & $\mathrm{PE}$ & $92 \%$ & \\
\hline NET-2019-014_M_IND-002 & 4.1 & 3.8 & 2.3 & 0.0200 & PS & $92 \%$ & \\
\hline NET-2019-014_M_IND-003 & 5.1 & 3.8 & 4.3 & 0.0515 & lonomer & $89 \%$ & \\
\hline NET-2019-015_M_IND-001 & 2.7 & 2.2 & 2.2 & 0.0112 & PE & $92 \%$ & \\
\hline NET-2019-018_M_IND-001 & 2.5 & 2.5 & 2.2 & 0.0210 & lonomer & $92 \%$ & * \\
\hline NET-2019-020_M_IND-001 & 4 & 3.9 & 2.5 & 0.0200 & PE & $95 \%$ & * \\
\hline NET-2019-020_M_IND-002 & 5.1 & 3.1 & 3 & 0.0252 & PP & $85 \%$ & \\
\hline NET-2019-021_M_IND-001 & 3.4 & 2.9 & 3.9 & 0.0273 & PP & $90 \%$ & \\
\hline NET-2019-025_M_IND-001 & 4.9 & 4 & 4.4 & 0.0576 & $\mathrm{PE}$ & $94 \%$ & * \\
\hline NET-2019-026_M_IND-001 & 3.9 & 3.8 & 1.7 & 0.0157 & PE & $97 \%$ & * \\
\hline NET-2019-026_M_IND-002 & 2.9 & 2.7 & 4.4 & 0.0217 & SBS & $91 \%$ & \\
\hline NET-2019-026_M_IND-003 & 3.6 & 3.6 & 4 & 0.0196 & SBS & $91 \%$ & \\
\hline NET-2019-032_M_IND-001 & 2.1 & 1.5 & 1.4 & 0.0029 & PE oxydized & $93 \%$ & * \\
\hline NET-2019-033_M_IND-001 & 2.6 & 2.6 & 2.8 & 0.0117 & HDPE & $95 \%$ & * \\
\hline NET-2019-042_M_IND-001 & 2.7 & 2.6 & 3.7 & 0.0193 & $\mathrm{PP}$ & $88 \%$ & \\
\hline NET-2019-044_M_IND-001 & 4.3 & 2.9 & 2.5 & 0.0193 & PP & $87 \%$ & \\
\hline NET-2019-044_M_IND-002 & 3.5 & 3.4 & 3.9 & 0.0284 & Microcrystalline Wax & $92 \%$ & \\
\hline NET-2019-045_M_IND-001 & 4 & 3.9 & 2.2 & 0.0245 & PE & $95 \%$ & \\
\hline NET-2019-045_M_IND-002 & 4.2 & 3.4 & 3 & 0.0269 & $\mathrm{PE}$ & $95 \%$ & \\
\hline NET-2019-045_M_IND-003 & 3.9 & 3.7 & 4.4 & 0.0487 & EVA & $94 \%$ & \\
\hline NET-2019-045_M_IND-004 & 4.2 & 4 & 1.9 & 0.0177 & PE & $96 \%$ & * \\
\hline NET-2019-047_M_IND-001 & 3.9 & 3.9 & 2.9 & 0.0200 & $\mathrm{PE}$ & $95 \%$ & \\
\hline NET-2019-047_M_IND-002 & 3.1 & 2.9 & 2.9 & 0.0151 & $\mathrm{PE}$ & $97 \%$ & * \\
\hline NET-2019-047_M_IND-003 & 3.8 & 3.3 & 3.4 & 0.0249 & $\mathrm{PE}$ & $97 \%$ & * \\
\hline NET-2019-047_M_IND-004 & 4.9 & 4.4 & 2.3 & 0.0275 & $\mathrm{PE}$ & $95 \%$ & * \\
\hline NET-2019-047_M_IND-005 & 5 & 3.9 & 3 & 0.0339 & ABS & $88 \%$ & \\
\hline NET-2019-047_M_IND-006 & 3.9 & 3.3 & 3.5 & 0.0245 & $\mathrm{PE}$ & $94 \%$ & * \\
\hline NET-2019-047_M_IND-007 & 2.8 & 2.7 & 3.2 & 0.0152 & PE & $97 \%$ & * \\
\hline NET-2019-047_M_IND-008 & 4.3 & 3.9 & 1.8 & 0.0135 & PE & $95 \%$ & * \\
\hline Gemiddeld stormvogels $2019(=36)$ & 3.744 & 3.34 & 2.958 & 0.0231 & & & \\
\hline Gemiideld Zoe pellets $(n=100)$ & 4.1 & 4.1 & 2.26 & 0.0236 & & & \\
\hline $\min$ & 3.8 & 3.8 & 1.8 & 0.0192 & & & \\
\hline $\max$ & 4.4 & 4.4 & 3 & 0.0328 & & & \\
\hline
\end{tabular}


Wageningen Marine Research

T: $+31(0) 317480900$

E: marine-research@wur.nl

www.wur.nl/marine-research

Bezoekers adres:

- Ankerpark 271781 AG Den Helder

- Korringaweg 7, 4401 NT Yerseke

- Haringkade 1, 1976 CP IJmuiden
Wageningen Marine Research levert met kennis, onafhankelijk wetenschappelijk onderzoek en advies een wezenlijke bijdrage aan een duurzamer, zorgvuldiger beheer, gebruik en bescherming van de natuurlijke rijkdommen in zee-, kust- en zoetwatergebieden.
Wageningen Marine Research is onderdeel van Wageningen University \& Research. Wageningen University \& Research is het samenwerkingsverband tussen Wageningen University en Stichting Wageningen Research en heeft als missie: 'To explore the potential of nature to improve the quality of life' 